\title{
Comparison of the diagnostic accuracy of commercial NS1-based diagnostic tests for early dengue infection
}

\author{
Lyda Osorio $^{1 *}$, Meleny Ramirez ${ }^{1}$, Anilza Bonelo², Luis A Villar ${ }^{3}$, Beatriz Parra²
}

\begin{abstract}
Background: We compared the diagnostic accuracy and reproducibility of commercially available NS1-based dengue tests and explored factors influencing their sensitivities.

Methods: Paired analysis of 310 samples previously characterized as positive $(n=218)$ and negative $(n=92)$ for viral isolation and/or RT-PCR and/or IgM seroconversion. Masked samples were tested by two observers with

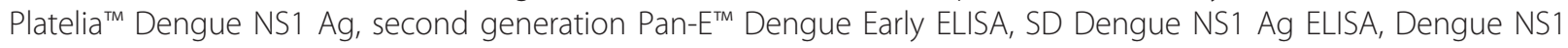
Ag STRIPTM, and SD BIOLINE ${ }^{\text {TM }}$ Dengue Duo (NS1/lgM/lgG).

Results: SD BIOLINE ${ }^{\mathrm{TM}} \mathrm{NS} 1 / \mathrm{lgM} / \mathrm{lgG}$ had the highest sensitivity $(80.7 \% 95 \% \mathrm{Cl} 75-85.7$ ) with likelihood ratios of 7.4 (95\% Cl 4.1-13.8) and 0.21 (95\% Cl 0.16-0.28). The ELISA-format tests showed comparable sensitivities; all below $75 \%$. STRIP ${ }^{\text {TM }}$ and SD NS1 had even lower sensitivities (<65\%). The sensitivities significantly decreased in samples taken after 3 days of fever onset, in secondary infections, viral serotypes 2 and 4 , and severe dengue. Adding $\operatorname{lgM}$ or $\lg G$ to SD NS1 increased its sensitivity in all these situations.

Conclusions: The simultaneous detection of NS1/lgM/lgG would be potentially useful for dengue diagnosis in both endemic and non endemic areas. A negative result does not rule out dengue. Further studies are required to assess the performance and impact of early laboratory diagnosis of dengue in the routine clinical setting.
\end{abstract}

\section{Background}

Dengue is a vector borne disease rapidly spreading in urban areas in tropical and subtropical countries. It is estimated that at least $10 \%$ of dengue fever cases evolve to severe and eventually lethal forms of the disease. The clinical and laboratory findings in dengue are very similar to those of other febrile diseases that are prevalent in the same geographical regions [1]. Therefore, a dengue diagnostic test is required for adequate case management and to reduce misclassification in the dengue surveillance system. However, dengue diagnosis in the first days of fever is yet problematic.

There are three main laboratory methods to diagnose dengue infection: viral isolation in culture, detection of viral RNA, and specific IgM/IgG antibodies in paired

\footnotetext{
* Correspondence: lyda10so@gmail.com

'Grupo de Epidemiologia y Salud Poblacional (GESP) Escuela de Salud Publica, Facultad de Salud, Universidad del Valle. Cali, Colombia Calle 4b 36-140, Cali-Colombia

Full list of author information is available at the end of the article
}

sera. The gold standard is usually a combination of these methods [1,2]. Viral isolation is costly, the results are usually available after 6 to 10 days and it is only obtainable in laboratories with the appropriate infrastructure for cell culture or mosquito colonies. The RTPCR and other PCR-based techniques give results within 24 hours but they are also costly and they are not available for most clinicians. On the contrary, there are commercially available immunochromatographic and ELISA tests for the detection of $\operatorname{IgM} / \operatorname{IgG}$ antibodies which give results within minutes or few hours. However, the detection of antibodies in a dengue infected person is only possible after 4-5 days of disease onset. Moreover, a single positive IgM or IgG result suggests recent infection but paired sera samples showing seroconversion or a fourfold titer increase are required to confirm diagnosis [1].

Recently, several dengue diagnostic tests based on the detection of NS1 (Non-structural Protein 1) have become commercially available. NS1 is a highly 


\begin{tabular}{|c|c|c|c|}
\hline Test & $\begin{array}{c}\text { Sensitivity \% } \\
\text { (95\%IC) }\end{array}$ & $\begin{array}{c}\text { Specificity \% } \\
\text { (95\%Cl) }\end{array}$ & place \\
\hline STRIP'M & $61.6(55.2-67.8)$ & $100(93.8-100)$ & Vietnam [6] \\
\hline $\operatorname{PanE}^{\mathrm{TM}}$ & $49.4(38.5-60.4)$ & $100(92.1-100)$ & India [7] \\
\hline STRIPTM & $78.9(70-86.1)$ & 99 (94.6-99.9) & Singapore [8] \\
\hline $\operatorname{Pan} E^{T M}$ & $67(57.3-75.7)$ & 100 (96.4-100) & Singapore [8] \\
\hline Platelia ${ }^{\mathrm{TM}}$ & $81.7(73.1-88.4)$ & $100(96.4-100)$ & Singapore [8] \\
\hline STRIPTM & $89.6(84.7-93.2)$ & 99.1 (96.9-99.9) & Brazil [9] \\
\hline $\operatorname{Pan} E^{T M}$ & $72.3(65.8-78.1)$ & $100(98.4-100)$ & Brazil [9] \\
\hline Platelia $^{\mathrm{TM}}$ & $83.6(78.1-88.2)$ & 98.7 (96.2-99.7) & Brazil [9] \\
\hline Platelia ${ }^{\mathrm{TM}}$ & $67.3(57.1-76.4)$ & - & Finland [10] \\
\hline Platelia ${ }^{\mathrm{TM}}$ & 37 & 99.5 & Vietnam [5] \\
\hline Platelia $^{\mathrm{TM}}$ & 73.6 (63.7-81.6 & - & Australia [11] \\
\hline $\operatorname{Pan} E^{T M}$ & 63.7 (53.5-72). & - & Australia [11] \\
\hline Platelia ${ }^{\mathrm{TM}}$ & $83.2(75.5-89.3)$ & $100(86.7-100.0)$ & Vietnam [12] \\
\hline Platelia ${ }^{\mathrm{TM}}$ & $71.3(61-80)$ & 86.1 (70.9-94.4) & Venezuela [13] \\
\hline Pan $E^{T M}$ & $60.9(50.4-70.5)$ & $94.4(80.9-99.4)$ & Venezuela [13] \\
\hline STRIPTM & $67.8(57.4-76.7)$ & $94.4(80.9-99.4)$ & Venezuela [13] \\
\hline STRIPTM & $90.4(86.6-94.4)$ & 99.5 (97.4-99.9) & Malaysia [14] \\
\hline STRIPTM & 98.9 (96.8-100) & $90.6(85.6-95.7)$ & Thailand [15] \\
\hline STRIPTM & $77.3(0.54-0.92)$ & 100 & Taiwan [16] \\
\hline Pan $E^{T M}$ & $83.3(65.2-94.3)$ & - & China [17] \\
\hline Platelia $^{\mathrm{TM}}$ & $63.2(55.7-70.0)$ & $98.4(91.7-99.7)$ & Thailand [18] \\
\hline Platelia ${ }^{\mathrm{TM}}$ & $83.2(77.5-87.7)$ & $100(92.1-100)$ & Puerto Rico [19] \\
\hline $\operatorname{PanE}^{\mathrm{TM}}$ & $64.9(58.2-71.1)$ & 97.8 (88.4-99.6) & Puerto Rico [19] \\
\hline STRIPTM & $77.6(72.1-82.4)$ & 100 (92.6-100) & French Guiana [20] \\
\hline Platelia $^{\mathrm{TM}}$ & $82.4(77.3-86.7)$ & $100(92.6-100)$ & French Guiana [20] \\
\hline Pan $E^{T M}$ & $55.1(49.0-61.2)$ & 97.9 (88.9-99.9) & French Guiana [20] \\
\hline Platelia $^{\text {TM }}$ & $92.3(64-99.8)$ & 100 & Thailand [21] \\
\hline $\operatorname{Pan} E^{T M}$ & $63(53-73)$ & 100 & Laos [22] \\
\hline Platelia $^{\mathrm{TM}}$ & $93.4(89.2-96.3)$ & $100(98.9-100)$ & Singapore [23] \\
\hline Platelia $^{\mathrm{TM}}$ & 88.7 (94-92.4) & $100(98.9-100)$ & French Guiana \\
\hline
\end{tabular}

conserved glycoprotein of flaviviruses including Dengue, Japanese encephalitis, Yellow fever and tick-borne encephalitis virus [3]. The specificity of the NS1-based Dengue tests is reported to be between $86.1 \%$ and $100 \%$ and false positives are considered rare $[4,5]$. Higher variability (between $37 \%$ and $98.9 \%$ ) has been reported in the sensitivity of these tests (Table 1) [6-24]. This variability could be partly explained by the fact that sensitivity has been found to decrease with time after fever onset and in secondary infections $[12,18,21]$. The addition of IgM and IgG specific antibodies detection to NS1-based tests in a single kit has been suggested [25] may improve the assessment of dengue infection status and one such test (SD BIOLINE ${ }^{\mathrm{mu}}$ Dengue Duo) has become commercially available. With all these options in the market, it is necessary to identify which of the current NS1-based diagnostic tests would be potentially more useful in the clinical setting. We sought to compare the performance of the current commercially available NS1-based assays for the early diagnosis (within 7 days since fever onset) of dengue infections. The objectives of this study were: 1) To identify differences in sensitivity, specificity, and likelihood ratios between all the diagnostic assays, 2) To describe the effect of duration of symptoms, type of infection, viral serotype, and severity of the disease on the sensitivity of the tests, and 3) to determine the reproducibility of each diagnostic test.

\section{Methods}

\section{Type of study and sample size calculation}

The study was a cross sectional case-reference design to assess diagnostic tests [26]. A paired analysis of samples from febrile subjects with and without dengue was done using viral isolation, RT-PCR or IgM seroconversion as gold standard. Sample size for dengue $(\mathrm{n}=210)$ and non-dengue $(\mathrm{n}=100)$ was estimated based on an expected $90 \%$ sensitivity and $100 \%$ specificity for the Platelia $^{\text {Tu }}$ test versus $80 \%$ sensitivity and $90 \%$ specificity for the other assays. The Conner method for the paired McNemar test was used for sample size calculation with a $5 \%$ alfa and $20 \%$ beta errors [27]. Half dengue and no dengue samples were used to assess reproducibility.

\section{Clinical samples}

Stored serum $(229,73.9 \%)$ or plasma $(81,26.1 \%)$ samples from febrile subjects with clinically-suspected dengue infection who took part in studies carried out by Universidad del Valle and Universidad Industrial de Santander in Colombia between 2004 and 2008 were selected randomly. The following criteria were considered: 1) dengue status known as a result of one or more of the following: viral isolation, RT-PCR or IgM seroconversion, 2) sample taken between day 0 and 7 of onset of fever, and 3) a minimum of $1 \mathrm{~mL}$ volume available. Day 0 was defined as the same day of fever onset. To avoid the spectrum bias, samples representing subjects who had been previously classified as dengue fever and hemorrhagic dengue were included and further classified as non-severe and severe dengue, respectively [1].

Gold standard tests (viral culture, nested RT-PCR or paired IgM) had been done during the previous studies at the virology laboratory of Universidad del Valle. Briefly, for viral isolation sera samples had been cultured in the mosquito cell line clone C6/36 HT and incubated at $33^{\circ} \mathrm{C}$ for 10 to 14 days. Viruses were detected and identified by immunofluoresce with serotype specific monoclonal antibodies 15F3 (DENV1), 3H5 (DENV2), 5D4 (DENV3) and 1H10 (DENV4) (Chemicon International, Inc. Temecula, California) and fluorescein isothiocyanate-conjugated goat anti-mouse antibody [28]. For RT-PCR, viral RNA had been extracted with trizol 
(Gibco-BRL, Gaithersburg, MD) and cDNA obtained with the reverse transcriptase of the Avian myeloblastosis virus (Promega, Madison, WI) and a dengue universal antisense primer targeting the C/prM region of the genome. cDNA amplification was performed with a nested PCR using the same universal dengue primers in a first round of amplification and viral serotype specific primers in a second round of PCR [29]. Finally, IgM MAC-ELISA in paired samples had been done using affinity-purified goat anti-human IgM as a capture antibody (KPL; Gaitersburg, Maryland $1 \mu \mathrm{g} / \mathrm{ml}$ ), followed by addition of 1:40 dilution of serum samples duplicates. Assay antigen was home-made and consisted of a mixture of 4 HA U (hemoagglutinating units) each of the four dengue serotypes obtained by i.c. inoculation of suckling mice and antigen extraction by a sucrose/acetone gradient. Detection was performed using 1:10,000 dilution of a peroxidase-conjugated dengue-complex specific monoclonal antibody MAB 6B6C-1 (kindly provided by CDC, San Juan de Puerto Rico) and substrate p-nitrophenyl-phosphate [30,31]. Positivity was defined as having an assay absorbance of $\geq 2.0(405 \mathrm{~nm})$ after subtracting the background value (negative sample).

Because up to $30 \%$ of secondary dengue infections do not have detectable IgM [32], and most non-dengue samples had been analyzed only by paired IgM, samples classified as non-dengue were further analyzed using an algorithm of RT-PCR plus IgG and IH. All non-dengue samples (except for four samples with insufficient volume left) were processed with RT-PCR as described elsewhere [29]. RT-PCR positives were considered as dengue. To discard secondary infections which do not increased IgM, all RT-PCR negative non-dengue samples underwent IgG detection in acute sera using Dengue Duo (IgM/IgG) Cassette (Inverness - Brisbane, Australia). Non-dengue samples with negative IgG were considered as true negatives. Those samples with positive IgG were processed with haemagglutinationinhibition test $(\mathrm{HI})$ and considered as true negatives if not increased $(>2560)$ titers were detected in convalescent sera (Figure 1). HI was done at the virology laboratory of Universidad del Valle using goose red blood cells and sucrose/acetone extracted antigens obtained in suckling mice brains following Kuno et al. 1991 [33]. This study was approved by the Universidad del Valle Ethics Review Board.

\section{Diagnostic tests and procedures}

All 5 diagnostic NS1-based tests commercially available at the time of the study were analyzed. These included: Platelia $^{\mathrm{m}}$ Dengue NS1 Ag Test (Bio-Rad Laboratories Marnes La Coquette, France), second generation Pan- $\mathrm{E}^{\mathrm{m}}$ Dengue Early ELISA (Inverness - Brisbane, Australia), Dengue NS1 Ag ELISA (Standard diagnostic Inc. -
Kyonggi-do - South Korea), Dengue NS1 Ag STRIP ${ }^{\mathrm{m}}$ (Bio-Rad), and SD BIOLINE ${ }^{\text {ma }}$ Dengue Duo (Standard diagnostic Inc.). The characteristics of the tests are summarized in table 2. The Platelia ${ }^{\text {ma }}$ Dengue NS1 Ag Test and Dengue NS1 Ag STRIP ${ }^{\mathrm{m} x}$ were purchased from the local distributor while the rest were kindly donated by the manufacturers. All tests were run following the corresponding manufacturer's instructions. Dengue NS1 Ag STRIP $^{\mathrm{Tw}}$ was read at $15 \mathrm{~min}$ and $30 \mathrm{~min}$. Three separate results were obtained from SD BIOLINE ${ }^{m}$ Dengue Duo test based on the results of NS1 only (dengue if NS1 was positive and non-dengue if NS1 was negative, regardless of IgM/IgG results), NS1/IgM combined (dengue if one of NS1 or IgM was positive and nondengue if both were negative, regardless of IgG results), and NS1/IgM/IgG combined (dengue if at least one of NS1, IgM or IgG was positive and non-dengue if all three were negative). Batches of samples were analyzed by all the NS1-based diagnostic tests on the same day and by the same persons who were two experienced lab scientists. Both observers were blind to the samples dengue status and each other results. Results of the ELISAbased format tests given as "equivocal" were repeated once. Persistent equivocal results were excluded from the analysis. Those results of the immunochromatography-based format tests given as "weak" were considered as positive results.

\section{Statistical analysis}

Data were double entered and validated using Epinfo (Centers for Disease Control and Prevention, USA, 2000). Stata 10 (Stata Corporation, 2003) was used for statistical analyses. First observer results were used to obtain sensitivity, specificity, negative (NPV) and positive (PPV) predictive values, positive and negative likelihood ratios (LR) with their corresponding $95 \%$ confidence intervals. Cochrane $Q$ was used to compare overall performance of ELISA tests and of immunocromatographic tests. McNemar Chi squared test or the equivalent exact test was used to compare the diagnostic accuracy among each possible pair of assays. The method proposed by RoldanNofuentes and Del Castillo (2007) was used to identify significant statistical differences in the LR of all tests [34] and carried out in Mathematica 7 (Wolfram Research Inc., 2010). Sensitivities with their corresponding $95 \%$ confidence intervals were also calculated by stratum of duration of symptoms ( $\leq 3$ and 4-7 days), primary/ secondary infection (defined as absence/presence of specific IgG in acute sera based on the results of the SD Bioline $^{\mathrm{m}}$ Dengue Duo), severe and non severe infection, and viral serotype. Reproducibility of the tests (inter-observer agreement) was assessed using Kappa indexes (k). We interpreted $\mathrm{k}$ results as follows: values of less than 0 , poor; 


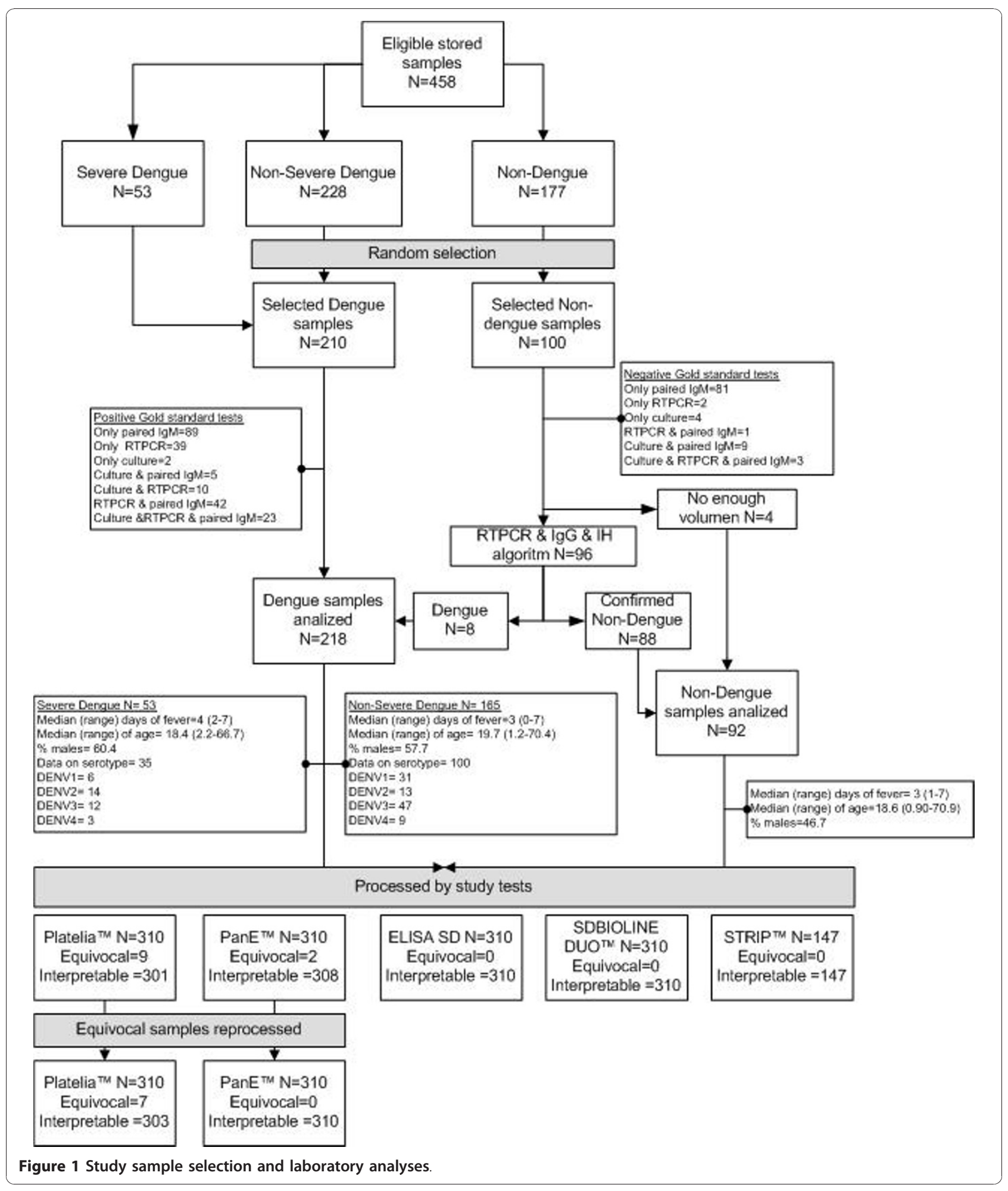

0 to 0.2 , slight; 0.2 to 0.4 , fair agreement; 0.4 to 0.6 , moderate agreement; 0.6 to 0.8 , substantial agreement; and values of 0.8 to 1.0 almost perfect agreement [35]. Funds allowed us to purchase a limited number of Dengue NS1
Ag STRIP ${ }^{\mathrm{Tm}}$ and hence results were available for 147 samples (104 dengue and 43 non-dengue). It was not possible to assess reproducibility of this test. A P value $<5 \%$ was considered as statistically significant. 
Table 2 Characteristics of the evaluated NS1-based dengue diagnostic tests

\begin{tabular}{|c|c|c|c|c|c|}
\hline Test name & $\begin{array}{l}\text { Platelia }^{\mathrm{TM}} \\
\text { Dengue } \\
\text { NS1 Ag Test }\end{array}$ & $\begin{array}{c}\text { Pan- } \mathrm{E}^{\mathrm{TM}} \\
\text { Dengue } \\
\text { Early }\end{array}$ & $\begin{array}{l}\text { SD Dengue } \\
\text { NS1 Ag }\end{array}$ & $\begin{array}{c}\text { Dengue NS1 } \\
\text { Ag STRIP }{ }^{T M}\end{array}$ & $\begin{array}{c}\text { SD BIOLINE } \\
\text { Dengue Duo test }\end{array}$ \\
\hline Company & Bio-Rad & Inverness & $\begin{array}{c}\text { Standard } \\
\text { diagnostic Inc }\end{array}$ & Bio-Rad & Standard diagnostic Inc \\
\hline Country & France & Australia & South Korea & France & South Korea \\
\hline Method of detection & ELISA & ELISA & ELISA & Immunochromatography & Immunochromatography \\
\hline Number of tests per pack & 96 & 96 & 96 & 25 & 1 (of each NS1, IgM and IgG) \\
\hline $\begin{array}{l}\text { Volume of sample } \\
\text { required }\end{array}$ & $50 \mu \mathrm{L}$ & $60-75 \mu \mathrm{L}$ & $50 \mu \mathrm{L}$ & $50 \mu \mathrm{L}$ & $\begin{array}{c}85 \mu \mathrm{L} \text { (75 for NS1 plus } 10 \text { for } \\
\text { lgM/lgG) }\end{array}$ \\
\hline Time to result & $2.5 \mathrm{~h}$ & $2.5 \mathrm{~h}$ & $2.5 \mathrm{~h}$ & $15-30 \mathrm{~min}$ & $20 \mathrm{~min}$ \\
\hline $\begin{array}{l}\text { Additional equipment } \\
\text { required? }\end{array}$ & Yes & Yes & Yes & No & No \\
\hline
\end{tabular}

\section{Results}

A total of 310 samples were included in the study from which 210 were classified as dengue and 100 as nondengue. Eight samples initially classified as non-dengue based on IgM negative results in paired serum samples were RT-PCR-positive and hence were reclassified as dengue. Therefore, for the final analysis there were 218 dengue and 92 non-dengue cases. Samples represented all age groups and had a median of 3 days of fever onset. Nine samples analyzed by Platelia ${ }^{\text {Tw }}$ and 2 by Pan $\mathrm{E}^{\mathrm{m}}$ gave equivocal results and were run twice. The second time, both Pan $\mathrm{E}^{\mathrm{mm}}$ and 2 Platelia $^{\mathrm{mm}}$ results were negative while the other 7 ( 1 non-dengue and 6 dengue) remained equivocal and were excluded from the final analyses (Figure 1). Sixty four (29.4\%) dengue samples were positive for IgG in the SD Bioline ${ }^{\text {mu }}$ Dengue Duo and were considered as secondary infections. Secondary infections had a median of 4 (range 2-7) days of fever onset and dengue serotype was identified in 42 of these cases: 13 DENV1, 17 DENV2, 7 DENV3, and 5 DENV4.

Sensitivity and specificity of tests ranged from $51 \%$ to $80.7 \%$ and from $89.1 \%$ to $96.7 \%$, respectively (Table 3 ). $\mathrm{SD}^{\mathrm{BIOLINE}}{ }^{\mathrm{Tm}} \mathrm{NS} 1 / \mathrm{IgM} / \mathrm{IgG}$ had the highest sensitivity (80.7\% 95\%CI 75-85.7) followed by SD BIOLINE ${ }^{\mathrm{mm}}$ NS1/ IgM (78.4\% 95\%CI 72.4-83.7) and Pan $\mathrm{E}^{\mathrm{mm}}(71.1 \%$ 95\%CI 64.6-77). There were not statistically significant differences in the diagnostic accuracy of the three ELISAbased assays $(p=0.9)$. For the immunocromatographic tests, STRIP ${ }^{\mathrm{ma}}$ read at $30 \mathrm{~min}$ had a higher diagnostic accuracy $(71.4 \%, 105 / 147)$ than STRIP ${ }^{\mathrm{st}}$ read at $15 \mathrm{~min}$ $(68.7 \%, 101 / 147)$ but this difference was not statistically significant $(\mathrm{p}=0.1)$. The diagnostic accuracy did not differ among SD BIOLINE ${ }^{\text {tw }}$ NS1/IgM $(82.2 \%$, 255/310) and SD BIOLINE ${ }^{\mathrm{mi}} \mathrm{NS1} / \operatorname{IgM} / \operatorname{IgG} 83.2,258 / 310$ (p = 0.4). However, their diagnostic accuracy was higher than all the other immunochromatographic and ELISA tests ( $<<0.05$ for all pair wise comparisons).

In line with the relatively high specificity found, the PPVs were above $90 \%$ for all tests. In contrast, the highest NPV was $66.1 \%$ (95\%CI 57.1-74.4). LR+ varied between 6.5 and 15.6 while LR-varied between 0.2 and 0.5 (Table 3). Statistically significant differences in LR were found between all tests pair wise comparisons except Platelia $^{\mathrm{mi}}$ Vs. PanE ${ }^{\mathrm{mm}}$, Platelia ${ }^{\mathrm{mm}}$ Vs. STRIP ${ }^{\mathrm{ms}}$, and ELISA SD ${ }^{\mathrm{ma}}$ Vs. STRIP ${ }^{\mathrm{m}}$. The sensitivity of NS1-based diagnostic tests significantly decreased in those samples taken after 3 days of fever onset, in secondary infections, viral serotypes 2 and 4, and severe dengue. Adding IgM or IgG to SD BIOLINE ${ }^{\mathrm{mm}}$ NS1 increased its sensitivity in all these situations (Figure 2). The positive effect of adding IgM to NS1 in the sensitivity of the test was more noticeable in samples with detectable IgG regardless of the days of fever onset (Table 4).

The inter-observer agreement was almost perfect for Pan $\mathrm{E}^{\mathrm{mm}}\left(\mathrm{k}=0.94\right.$ CI95\% 0.88-0.99), ELISA SD ${ }^{\mathrm{mm}}(\mathrm{k}=0.89$ CI95\% 0.82-0.96), SD BIOLINE ${ }^{\text {tu }}$ NS1 ( $k=0.90$ CI95\% 0.83-0.98), and the IgM cassette of SD BIOLINE ${ }^{\mathrm{TM}}(\mathrm{k}=$ 0.85 CI95\% 0.76-0.94) while substantial agreement was observed with Platelia ${ }^{\text {Tx }}(\mathrm{k}=0.75$ CI95\% 0.60-0.89) and the IgG cassette of SD BIOLINE ${ }^{\mathrm{ma}}(\mathrm{k}=0.7$ CI95\% 0.56-0.84).

\section{Discussion}

In the present study we compared simultaneously the performance of 5 commercially available tests for the early (within 7 days of fever onset) diagnosis of dengue. 
Table 3 Measures of performance of commercially available NS1 detection-based dengue diagnostic assays

\begin{tabular}{|c|c|c|c|c|c|c|c|c|c|c|}
\hline Assay & $\begin{array}{l}\text { Dengue } \\
\text { samples }\end{array}$ & $\begin{array}{l}\text { Non-dengue } \\
\text { samples }\end{array}$ & $\begin{array}{l}\text { Positive } \\
\text { tests }\end{array}$ & $\begin{array}{l}\text { Negative } \\
\text { tests }\end{array}$ & $\begin{array}{c}\text { Sensitivity \% } \\
(95 \% \mathrm{Cl})\end{array}$ & $\begin{array}{l}\text { Specificity \% } \\
(95 \% \mathrm{Cl})\end{array}$ & $\begin{array}{l}\text { PPV \% } \\
(95 \% \text { Cl) }\end{array}$ & $\begin{array}{l}\text { NPV \% } \\
(95 \% \text { Cl) }\end{array}$ & $\begin{array}{c}\mathrm{LR}+ \\
(95 \% \mathrm{Cl})\end{array}$ & $\begin{array}{c}\text { LR- } \\
(95 \% \mathrm{Cl})\end{array}$ \\
\hline \multirow[t]{2}{*}{ Platelia $^{\mathrm{TM}}$} & 212 & 91 & 150 & 84 & 70.8 & 92.3 & 95.5 & 57.5 & 9.2 & 0.31 \\
\hline & & & & & $(64.1-76.8)$ & $(84.8-96.9)$ & $(91-98.2)$ & $(49.1-65.7)$ & $(4.5-18.8)$ & $(0.25-0.39)$ \\
\hline \multirow[t]{2}{*}{$\operatorname{PanE}^{\mathrm{TM}}$} & 218 & 92 & 155 & 82 & 71.1 & 89.1 & 94 & 56.6 & 6.54 & 0.32 \\
\hline & & & & & $(64.6-77)$ & $(80.9-94.7)$ & $(89.1-97.1)$ & $(48.1-64.8)$ & $(3.62-11.8)$ & $(0.26-0.4)$ \\
\hline \multirow[t]{2}{*}{ ELISA SD ${ }^{\mathrm{TM}}$} & 218 & 92 & 150 & 87 & 68.8 & 94.6 & 96.8 & 56.1 & 12.7 & 0.33 \\
\hline & & & & & $(62.2-75)$ & $(87.8-98.2)$ & $(92.6-99)$ & $(48-64.1)$ & $(5.37-29.8)$ & $(0.27-0.4)$ \\
\hline SD Bioline ${ }^{\mathrm{TM}}$ & 218 & 92 & 111 & 89 & 51 & 96.7 & 97.4 & 45.4 & 15.6 & 0.5 \\
\hline NS1 only & & & & & $(44.1-57.7)$ & (90.8-99.3) & $(92.5-99.5)$ & $(38.3-52.7)$ & $(5.1-48)$ & $(0.44-0.58)$ \\
\hline SD Bioline ${ }^{\mathrm{TM}}$ & 218 & 92 & 171 & 84 & 78.4 & 91.3 & 95.5 & 64.1 & 9.02 & 0.23 \\
\hline NS1/lgM & & & & & (72.4-83.7) & $(83.6-96.2)$ & $(91.4-98.1)$ & $(55.3-72.3)$ & $(4.64-17.6)$ & $(0.18-0.3)$ \\
\hline SD Bioline ${ }^{\mathrm{TM}}$ & 218 & 92 & 176 & 82 & 80.7 & 89.1 & 94.6 & 66.1 & 7.43 & 0.21 \\
\hline NS1/lgM/lgG & & & & & $(75-85.7)$ & $(81-94.7)$ & $(90.3-97.4)$ & $(57.1-74.4)$ & $(4.12-13.8)$ & $(0.16-0.28)$ \\
\hline STRIP'M & 104 & 43 & 60 & 41 & 57.7 & 95.3 & 96.8 & 48.2 & 12.4 & 0.44 \\
\hline $15 \mathrm{~min}$ & & & & & $(47.6-67.3)$ & $(84.2-99.4)$ & (88.8-99.6) & (37.3-59.3) & $(3.17-48.5)$ & $(0.35-0.56)$ \\
\hline STRIPTM & 104 & 43 & 64 & 41 & 61.5 & 93.3 & 97 & 50.6 & 13.2 & 0.4 \\
\hline $30 \mathrm{~min}$ & & & & & $(51.5-70.9)$ & $(84.2-99.4)$ & (89.5-99.6) & $(39.3-62)$ & $(3.4-51.6)$ & $(0.31-0.5)$ \\
\hline
\end{tabular}

PPV = Positive Predictive Value, NPV $=$ Negative Predictive Value, $L R=$ Likelihood Ratio

The sensitivity (51\% to $80.7 \%)$ and specificity $(89.1 \%$ to 96.7\%) of the NS1-based tests found in the present study fell within the range described elsewhere (Table 1). In previous comparative studies the sensitivity of Platelia ${ }^{\mathrm{Tm}}(71.3 \%-87.4 \%)$ was consistently higher than STRIP $^{\text {ma }}(67.8 \%-82.4 \%)$ and, in turn, the sensitivity of STRIP $^{\text {тм }}$ was higher than Pan $\mathrm{E}^{\mathrm{Tм}}(60.4 \%-64.9 \%)$. By contrast, we did not find differences in the diagnostic accuracy of the ELISA-format diagnostic tests (Platelia ${ }^{\mathrm{TM}}$, Pan $\mathrm{E}^{\mathrm{TM}}$ and ELISA $\mathrm{SD}^{\mathrm{rm}}$ ). In the present study, Pan $\mathrm{E}^{\mathrm{TM}}$ sensitivity was higher than in the previous reports probably because we used Pan $\mathrm{E}^{\mathrm{TM}}$ second generation, which uses less diluted controls and samples (1:2 instead 1:10) than the previous version [36]. Despite ELISA-format tests showing comparable sensitivities, they were all below $75 \%$. The immunocromatographic-format tests that detect only NS1 had even lower sensitivities. This means that a negative result on any of these tests does not rule out dengue. The immunocromatographic SD Bioline $^{\mathrm{Tm}}$ that detects simultaneously NS1 and specific IgM/IgG showed the highest sensitivity (80.7\% CI95\% $75-85.7)$ which was comparable to the $83.7 \%$ (95\%CI 78.4 - 88.1) reported in Vietnam [6]. Similarly, the addition of IgM has shown to improve the sensitivity of NS1 ELISA-format tests from $63.2 \%$ to $79 \%$ on admission samples without significantly decreasing specificity [22]. Although we did not find statistically significant differences in the addition of IgM only or both antibodies to NS1, the use of IgG could have clinical significance when correlated with disease evolution and the days of fever onset. In any case, a positive result for IgM or IgG in a single sample does not confirm dengue, therefore; the impact of false positives in the routine clinical setting should be assessed.

Predictive values depend on the prevalence of the disease but their trend here showed that all tests were comparable. For potential clinical use, LR measures of diagnostic tests performance are more useful than predictive values. They tell how the test results modified the pretest probability of disease independent of its prevalence. LR values above 10 and below 0.1 are considered conclusive to rule in or rule out diagnoses, respectively while values of 5 to 10 and 0.1 to 0.2 are frequently helpful to take clinical decisions [37]. In a scenario where a clinician's interest is to confirm dengue diagnosis any of the tests is likely to be useful but they should be aware that a negative test does not rule out dengue. Hence, further diagnostics such as paired IgM or IgG to assess seroconversion or titer increase would need to be done. On the contrary, if ruling out dengue 


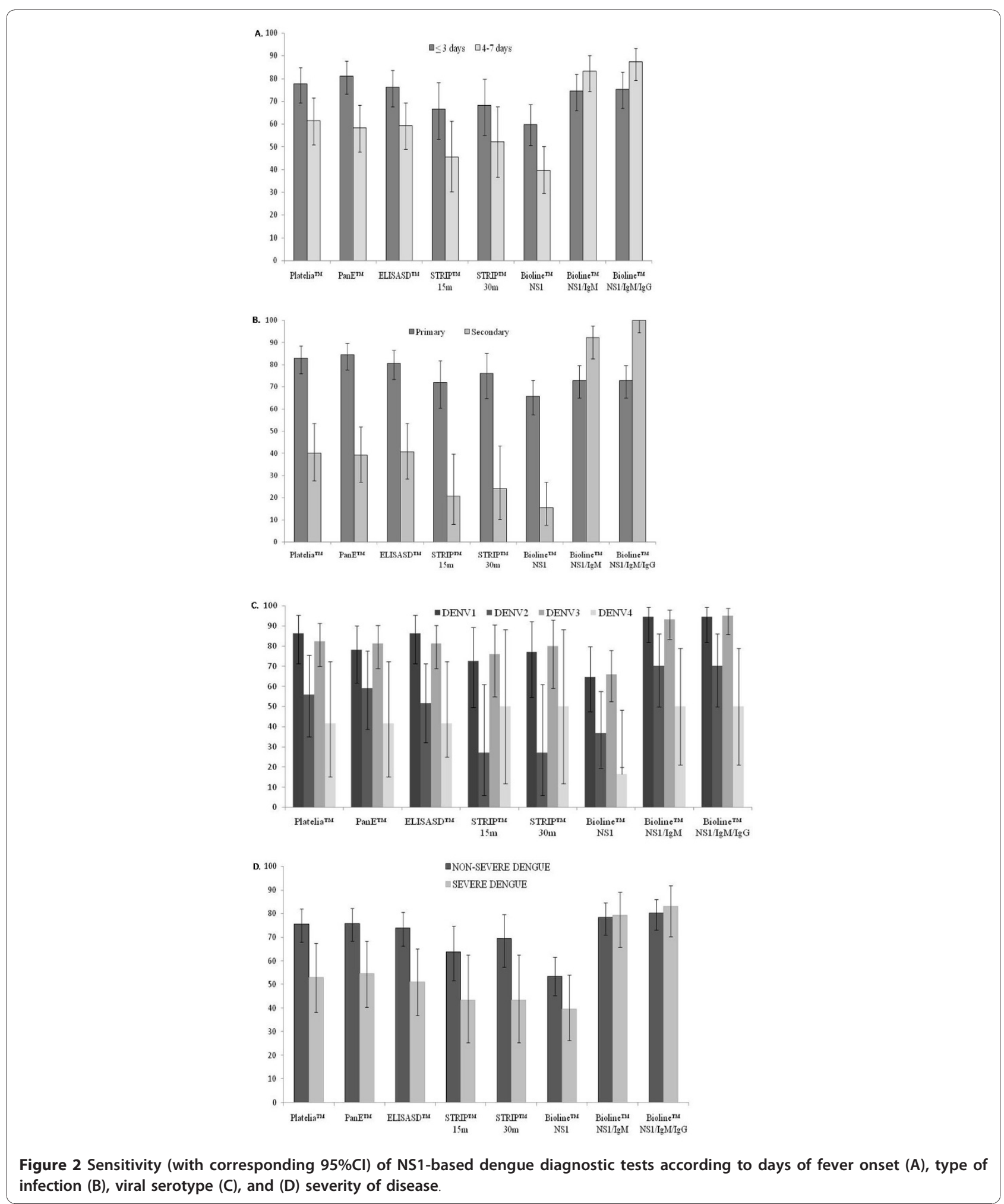

is important for clinical decision then the SD Bioline ${ }^{\mathrm{TM}}$ $\mathrm{NS} 1 / \operatorname{IgM} / \mathrm{IgG}$ would provide more useful information than any of the other tests $(L R=0.21)$. However, it ought not to be considered as a screening test. Further studies with larger sample size would be required to give more precise estimates of LR.

The simultaneous detection of NS1 and specific IgM/ IgG appeared to overcome the limitations of using only 
Table 4 Sensitivity of SD Bioline ${ }^{\mathrm{TM}}$ Dengue Duo according to presence of IgG and days of fever.

\begin{tabular}{|c|c|c|c|c|c|}
\hline \multirow{3}{*}{$\begin{array}{l}\text { Component of SD Bioline }{ }^{\mathrm{TM}} \\
\text { Dengue Duo analyzed }\end{array}$} & \multirow[b]{2}{*}{ Days of fever onset } & \multicolumn{2}{|c|}{ Negative IgG in acute sera } & \multicolumn{2}{|c|}{ Positive IgG in acute sera } \\
\hline & & 0 to 3 & 4 to 7 & 0 to 3 & 4 to 7 \\
\hline & Dengue samples & $N=108$ & $N=46$ & $\mathrm{~N}=14$ & $\mathrm{~N}=50$ \\
\hline \multirow[t]{3}{*}{ Only NS1 } & Positive tests & 71 & 30 & 2 & 8 \\
\hline & Sensitivity \% & 65.7 & 65.2 & 14.3 & 16 \\
\hline & $(95 \% \mathrm{Cl})$ & $(56-74.6)$ & $(49.8-78.6)$ & $(1.78-42.8)$ & $(7.17-29.1)$ \\
\hline \multirow[t]{3}{*}{ Any of NS1/lgM } & Positive tests & 78 & 34 & 13 & 46 \\
\hline & Sensitivity \% & 72.2 & 74 & 93 & 92 \\
\hline & $(95 \% \mathrm{Cl})$ & $(62.8-80.4)$ & $(59-85.7)$ & $(66.1-99.8)$ & $(80.8-97.8)$ \\
\hline \multirow[t]{3}{*}{ Any of NS1/lgM/lgG } & Positive tests & 78 & 34 & 14 & 50 \\
\hline & Sensitivity \% & 72.2 & 74 & 100 & 100 \\
\hline & $(95 \% \mathrm{Cl})$ & $(62.8-80.4)$ & $(59-85.7)$ & $(76.8-100)$ & $(92.9-100)$ \\
\hline
\end{tabular}

NS1-based diagnostic tests in secondary infections, in subjects who seek treatment after 3 days of disease onset and on severe cases. Our results confirmed that sensitivity of NS1-based tests decreased in secondary infections and with time of fever onset [12,18,20,21,23]. In contrast to Chaiyaratana et al. (2009), we also found a decreased sensitivity of all assays in severe cases because, in our study, these were more likely to be secondary infections ( $\mathrm{OR}=3,0195 \% \mathrm{CI} 1.57-5.78)$ and presented after 4 days of fever $(\mathrm{OR}=4.31$ 95\%CI 2.04-9.1) than non-severe infections [15]. The addition of IgM/ IgG appeared to increase the sensitivity of NS1 Bioline ${ }^{\mathrm{TM}}$ in all 4 dengue serotypes. Nevertheless, the sensitivities of all tests were consistently lower in DENV2 and DENV4 infections as was also observed in Venezuela [13] and Puerto Rico [19]. The frequency of secondary infections and time since disease onset could only partly explain these differences because, in our study, only DENV4 tended to be associated with the presence of IgG in acute sera and samples taken after 4 days of fever (data not shown). Viraemia levels were found to be significantly higher in DENV1 than DENV2 and DENV4 infected subjects in Vietnam [38]. Therefore, differences in viral loads could be an alternative explanation for the observed effect of serotype in NS1-based tests sensitivity. In spite of this, no differences in sensitivity of Platelia ${ }^{\text {TM }}$ and STRIP ${ }^{\mathrm{TM}}$ according to serotype had been reported in samples from French Guiana [20,24]. Therefore, other reasons such as a decreased avidity of NS1 tests for certain geographical dengue virus clades, as proposed before, could be explored [13].

One limitation of the present study was residual misclassification of non-dengue cases, which would underestimate the specificity of the tests. This is probably low because most negative (92/98) samples were analyzed by at least two gold standard methods. Confirmation of non-dengue diagnosis was not sought due to limited sample volume. Specificities were relatively high and similar to previous reports in South America [13]. Further misclassification is likely in secondary and primary infections as we did not use a gold standard method such as a quantitative HI due to limited funds and in some samples not enough available volume. The use of one of the study tests (SD Bioline ${ }^{\mathrm{rm}}$ ) to define presence of both IgG and IgM would tend to overestimate the sensitivity of IgM in secondary infections. Nevertheless, the findings were consistent with previous reports of the increased test sensitivity in secondary infections provided by the addition of IgM to NS1 [6]. Yellow Fever vaccination (YFV) also is a source of potential false positives with IgG but this information was not available for the study samples. YFV is recommended in Colombia and therefore it is important to include information on YFV status of subjects in future studies to assess the degree of misclassification.

\section{Conclusions}

Of the 5 tests assessed, SD Bioline ${ }^{\mathrm{Tm}}$ NS1/IgM/IgG performed significantly better than the other tests. Therefore, the simultaneous detection of NS1/IgM/IgG would be potentially useful to diagnose dengue in both endemic and non endemic areas. All NS1 tests were highly reproducible. Clinicians must be aware that a negative result does not rule out dengue. To take evidence based decisions about the usefulness of this test in clinical settings, it is recommended to assess its performance in consecutive subjects with potential dengue infection under routine conditions at health centers with different levels of complexity. Further studies are required to assess the potential impact of implementing early laboratory diagnosis of dengue in terms of prognosis and cost-effectiveness. Secondary infection, viral serotype and time since fever onset 
should be taken into account as sources of heterogeneity in the interpretation and meta-analysis of NS1-based diagnostic tests.

\section{Acknowledgements}

We are grateful to Jaime Muñoz, Natalia Basto, Graciela Rengifo, and Olga Lucia Agudelo at Univalle who contributed with sample selection, preparation and RT-PCR and HI tests and Dr. Ruth Martinez at UIS for her contribution in data collection. The statistical function for LR comparisons was kindly provided by Dr. José Antonio Roldan-Nofuentes. We thank the manufacturers who gently provided their tests kits.

This study was funded by Universidad del Valle Project ID 613 and Standard Diagnostics contract 13102009

\section{Author details}

'Grupo de Epidemiologia y Salud Poblacional (GESP) Escuela de Salud Publica, Facultad de Salud, Universidad del Valle. Cali, Colombia Calle 4b 36-140, Cali-Colombia. ${ }^{2}$ Grupo de investigación VIREM, Escuela de Ciencias Basicas, Facultad de Salud, Universidad del Valle. Cali, Colombia. Calle 4b 36-140, Cali-Colombia. ${ }^{3}$ Centro de Investigaciones Epidemiológicas y Centro de Investigaciones en Enfermedades Tropicales, Escuela de Medicina, Universidad Industrial de Santander, Sede Guatiguará Km 2 Autopista Piedecuesta, Santander, Colombia.

\section{Authors' contributions}

LO designed the study, conducted the data analysis and wrote the manuscript; MR designed the study, entered and analyzed the data and critically reviewed the manuscript; $A B$ contributed to acquisition of data and interpretation of the results, run the tests as a second observer and critically reviewed the manuscript; LAV contributed to acquisition of data and interpretation of the results, and critically reviewed the manuscript; BP contributed to acquisition of data and interpretation of the results, run the tests as a first observer and co-wrote the manuscript. All authors read and approved the final manuscript.

\section{Competing interests}

None of the authors have received any gifts, travel funds, have served as consultant, speaker or received previous funding from the diagnostic tests manufacturers. The present study was partially funded by Standard Diagnostics Inc. However, none of the diagnostic test manufacturers had a role, either directly or through a third party, in the gathering or preparation of data, in the writing of the manuscript or the decision to submit the manuscript for publication. There are not any other financial and nonfinancial competing interests.

Received: 6 August 2010 Accepted: 6 December 2010

Published: 6 December 2010

\section{References}

1. World Health Organization (WHO) and the Special Programme for Research and Training in Tropical Diseases: Dengue: guidelines for diagnosis, treatment, prevention and control - New edition. France 2009.

2. de Oliveira Poersch C, Pavoni DP, Queiroz MH, de Borba L, Goldenberg S, dos Santos CN, Krieger MA: Dengue virus infections: comparison of methods for diagnosing the acute disease. J Clin Virol 2005, 32(4):272-277.

3. Alcon-LePoder S, Sivard P, Drouet M, Talarmin A, Rice C, Flamand M: Secretion of flaviviral non-structural protein NS1: from diagnosis to pathogenesis. Novartis Found Symp 2006, 277:233-247;

4. Xu H, Di B, Pan Y, Qiu L, Wang Y, Hao W, He L, Yuen K, Che X: Serotype 1specific monoclonal antibody-based antigen capture immunoassay for detection of circulating nonstructural protein NS1: Implications for early diagnosis and serotyping of dengue virus infections. J Clin Microbiol 2006, 44:2872-2878.

5. Phuong H, Thai K, Nga T, Giao P, Hung Q, Binh T, Nam N, Groen J, de Vries P: Detection of dengue nonstructural 1 (NS1) protein in Vietnamese patients with fever. Diagn Microbiol Infect Dis 2009, 63:372-378.

6. Tricou V, Vu H, Quynh N, Nguyen C, Tran H, Farrar J, Wills B, Simmons C Comparison of two dengue NS1 rapid tests for sensitivity, specificity and relationship to viraemia and antibody responses. BMC Infect Dis 2010, 10:142.

7. Singh M, Majumdar M, Singh G, Goyal K, Preet K, Sarwal A, Mishra B, Ratho R: NS1 antigen as an early diagnostic marker in dengue: report from India. Diagn Microbiol Infect Dis 2010, 68:50-54.

8. Pok K, Lai Y, Sng J, Ng L: Evaluation of Nonstructural 1 Antigen Assays for the Diagnosis and Surveillance of Dengue in Singapore. Vector Borne Zoonotic Dis 2010.

9. Lima MR, Nogueira R, Schatzmayr H, dos Santos F: Comparison of three commercially available dengue NS1 antigen capture assays for acute diagnosis of dengue in Brazil. PLoS Negl Trop Dis 2010, 4:e738.

10. Huhtamo E, Hasu E, Uzcátegui N, Erra E, Nikkari S, Kantele A, Vapalahti O, Piiparinen $\mathrm{H}$ : Early diagnosis of dengue in travelers: comparison of a novel real-time RT-PCR, NS1 antigen detection and serology. J Clin Virol 2010, 47:49-53.

11. McBride W: Evaluation of dengue NS1 test kits for the diagnosis of dengue fever. Diagn Microbiol Infect Dis 2009, 64:31-36.

12. Hang V, Nguyet N, Trung D, Tricou V, Yoksan S, Dung N, Van Ngoc T, Hien T, Farrar J, Wills B, Simmons C: Diagnostic accuracy of NS1 ELISA and lateral flow rapid tests for dengue sensitivity, specificity and relationship to viraemia and antibody responses. PLoS Negl Trop Dis 2009, 3:e360.

13. Ramirez A, Moros Z, Comach G, Zambrano J, Bravo L, Pinto B, Vielma S, Cardier J, Liprandi F: Evaluation of dengue NS1 antigen detection tests with acute sera from patients infected with dengue virus in Venezuela. Diagn Microbiol Infect Dis 2009, 65:247-253.

14. Zainah S, Wahab A, Mariam M, Fauziah M, Khairul A, Roslina I, Sairulakhma A, Kadimon S, Jais M, Chua K: Performance of a commercial rapid dengue NS1 antigen immunochromatography test with reference to dengue NS1 antigen-capture ELISA. J Virol Methods 2009, 155:157-160.

15. Chaiyaratana W, Chuansumrit A, Pongthanapisith V, Tangnararatchakit K, Lertwongrath S, Yoksan S: Evaluation of dengue nonstructural protein 1 antigen strip for the rapid diagnosis of patients with dengue infection. Diagn Microbiol Infect Dis 2009, 64:83-84.

16. Shu P, Yang C, Kao J, Su C, Chang S, Lin C, Yang W, Shih H, Yang S, Wu PF, Wu HS, Huang JH: Application of the dengue virus NS1 antigen rapid test for on-site detection of imported dengue cases at airports. Clin Vaccine Immunol 2009, 16:589-591.

17. Qiu L, Di B, Wen K, Wang X, Liang W, Wang Y, Pan Y, Wang M, Ding Y, Che $X$ : Development of an antigen capture immunoassay based on monoclonal antibodies specific for dengue virus serotype 2 nonstructural protein 1 for early and rapid identification of dengue virus serotype 2 infections. Clin Vaccine Immunol 2009, 16:88-95.

18. Lapphra K, Sangcharaswichai A, Chokephaibulkit K, Tiengrim S, Piriyakarnsakul W, Chakorn T, Yoksan S, Wattanamongkolsil L, Thamlikitkul V: Evaluation of an NS1 antigen detection for diagnosis of acute dengue infection in patients with acute febrile illness. Diagn Microbiol Infect Dis 2008, 60:387-391.

19. Bessoff K, Delorey M, Sun W, Hunsperger E: Comparison of two commercially available dengue virus (DENV) NS1 capture enzyme-linked immunosorbent assays using a single clinical sample for diagnosis of acute DENV infection. Clin Vaccine Immunol 2008, 15:1513-1518.

20. Dussart P, Petit L, Labeau B, Bremand L, Leduc A, Moua D, Matheus S, Baril $L$ : Evaluation of two new commercial tests for the diagnosis of acute dengue virus infection using NS1 antigen detection in human serum. PLoS Negl Trop Dis 2008, 2:e280.

21. Chuansumrit A, Chaiyaratana W, Pongthanapisith V, Tangnararatchakit K, Lertwongrath S, Yoksan S: The use of dengue nonstructural protein 1 antigen for the early diagnosis during the febrile stage in patients with dengue infection. Pediatr Infect Dis J 2008, 27:43-48.

22. Blacksell S, Mammen MJ, Thongpaseuth S, Gibbons R, Jarman R, Jenjaroen K, Nisalak A, Phetsouvanh R, Newton P, Day N: Evaluation of the Panbio dengue virus nonstructural 1 antigen detection and immunoglobulin $\mathrm{M}$ antibody enzyme-linked immunosorbent assays for the diagnosis of acute dengue infections in Laos. Diagn Microbiol Infect Dis 2008, 60:43-49.

23. Kumarasamy V, Chua S, Hassan Z, Wahab A, Chem Y, Mohamad M, Chua K: Evaluating the sensitivity of a commercial dengue NS1 antigen-capture ELISA for early diagnosis of acute dengue virus infection. Singapore Med J 2007, 48:669-673.

24. Dussart P, Labeau B, Lagathu G, Louis P, Nunes M, Rodrigues S, StorckHerrmann C, Cesaire R, Morvan J, Flamand M, Baril L: Evaluation of an 
enzyme immunoassay for detection of dengue virus NS1 antigen in human serum. Clin Vaccine Immunol 2006, 13:1185-1189.

25. Arya S, Agarwal N: NS1 detection in addition to new dengue antibody assay with differential detection of IgG and IgM antibodies. Clin Biochem 2010, 43:537.

26. Knottnerus J, Muris J: Assessment of the accuracy of diagnostic tests: the cross-sectional study. J Clin Epidemiol 2003, 56:1118-1128.

27. Obuchowski N: Sample size calculations in studies of test accuracy. Stat Methods Med Res 1998, 7:371-392

28. Gubler D, Kuno G, Sather G, Velez M, Oliver A: Mosquito cell cultures and specific monoclonal antibodies in surveillance for dengue viruses. Am J Trop Med Hyg 1984, 33:158-165.

29. Lanciotti R, Calisher C, Gubler D, Chang G, Vorndam A: Rapid detection and typing of dengue viruses from clinical samples by using reverse transcriptase-polymerase chain reaction. J Clin Microbiol 1992, 30:545-551.

30. Innis B, Nisalak A, Nimmannitya S, Kusalerdchariya S, Chongswasdi V, Suntayakorn S, Puttisri P, Hoke C: An enzyme-linked immunosorbent assay to characterize dengue infections where dengue and Japanese encephalitis co-circulate. Am J Trop Med Hyg 1989, 40:418-427.

31. Centers for Disease Control and Prevention, and Pan-American Health Organization: Dengue laboratory diagnostic procedures for the Americas San Juan, Puerto Rico; 1981, 17-122.

32. Chanama S, Anantapreecha S, A-nuegoonpipat A, Sa-gnasang A, Kurane I, Sawanpanyalert $P$ : Analysis of specific lgM responses in secondary dengue virus infections: levels and positive rates in comparison with primary infections. J Clin Virol 2004, 31:185-189.

33. Kuno G, Gómez I, Gubler D: An ELISA procedure for the diagnosis of dengue infections. J Virol Methods 1991, 33:101-113.

34. Nofuentes J, Del Castillo JD: Comparison of the likelihood ratios of two binary diagnostic tests in paired designs. Stat Med 2007, 26:4179-4201.

35. Landis J, Koch G: The measurement of observer agreement for categorical data. Biometrics 1977, 33:159-174.

36. Inverness Medical Australia. [http://www. panbiodengue.com/story/ improved-panbio-dengue-early-elisa-available-now].

37. Guyatt G, Drummond R, Meade M, Cook D: User's guides to the medical literature: a manual for evidence-based clinical practice San Francisco: McGraw Hill; 2008

38. Thai $K$, Phuong $H$, Thanh Nga T, Giao P, Hung IQ, Van Nam N, Binh T, Simmons C, Farrar J, Hien TT, van Doorn HR, de Jong MD, de Vries PJ Clinical, epidemiological and virological features of Dengue virus infections in Vietnamese patients presenting to primary care facilities with acute undifferentiated fever. J Infect 2010, 60:229-237.

doi:10.1186/1743-422X-7-361

Cite this article as: Osorio et al:: Comparison of the diagnostic accuracy of commercial NS1-based diagnostic tests for early dengue infection. Virology Journal 2010 7:361.

\section{Submit your next manuscript to BioMed Central and take full advantage of:}

- Convenient online submission

- Thorough peer review

- No space constraints or color figure charges

- Immediate publication on acceptance

- Inclusion in PubMed, CAS, Scopus and Google Scholar

- Research which is freely available for redistribution

Submit your manuscript at www.biomedcentral.com/submit
Biomed Central 